Psychological Medicine

http://journals.cambridge.org/PSM

Additional services for Psychological Medicine:

PSYCHOLOGICAL

MEDICINE

Email alerts: $\underline{\text { Click here }}$

Subscriptions: $\underline{\text { Click here }}$

Commercial reprints: $\underline{\text { Click here }}$

Terms of use : $\underline{\text { Click here }}$

\title{
Course trajectories of unipolar depressive disorders identified by latent class growth analysis
}

D. Rhebergen, F. Lamers, J. Spijker, R. de Graaf, A. T. F. Beekman and B. W. J. H. Penninx

Psychological Medicine / Volume 42 / Issue 07 / July 2012, pp 1383 - 1396

DOI: 10.1017/S0033291711002509, Published online: 07 November 2011

Link to this article: http://journals.cambridge.org/abstract_S0033291711002509

How to cite this article:

D. Rhebergen, F. Lamers, J. Spijker, R. de Graaf, A. T. F. Beekman and B. W. J. H. Penninx (2012). Course trajectories of unipolar depressive disorders identified by latent class growth analysis. Psychological Medicine, 42, pp 1383-1396 doi:10.1017/S0033291711002509

Request Permissions : $\underline{\text { Click here }}$ 


\title{
Course trajectories of unipolar depressive disorders identified by latent class growth analysis
}

\author{
D. Rhebergen ${ }^{1 *}$, F. Lamers ${ }^{1}$, J. Spijker ${ }^{2,3}$, R. de Graaf ${ }^{2}$, A. T. F. Beekman ${ }^{1}$ and B. W. J. H. Pennin $x^{1}$ \\ ${ }^{1}$ Department of Psychiatry and the EMGO Institute for Health and Care Research, VU University Medical Center Amsterdam, The Netherlands \\ ${ }^{2}$ Netherlands Institute of Mental Health and Addiction, Utrecht, The Netherlands \\ ${ }^{3}$ De Gelderse Roos, Arnhem, The Netherlands
}

\begin{abstract}
Background. Current classification of unipolar depression reflects the idea that prognosis is essential. However, do DSM categories of major depressive disorder (MDD), dysthymic disorder (Dysth) and double depression $(\mathrm{DD}=\mathrm{MDD}+$ Dysth) indeed adequately represent clinically relevant course trajectories of unipolar depression? Our aim was to test DSM categories (MDD, Dysth and DD) in comparison with empirically derived prognostic categories, using a prospectively followed cohort of depressed patients.
\end{abstract}

Method. A large sample $(n=804)$ of out-patients with unipolar depression were derived from a prospective cohort study, the Netherlands Study of Depression and Anxiety (NESDA). Using latent class growth analysis (LCGA), empirically derived 2-year course trajectories were constructed. These were compared with DSM diagnoses and a wider set of putative predictors for class membership.

Results. Five course trajectories were identified, ranging from mild severity and rapid remission to high severity and chronic course trajectory. Contrary to expectations, more than $50 \%$ of Dysth and DD were allocated to classes with favorable course trajectories, suggesting that current DSM categories do not adequately represent course trajectories. The class with the most favorable course trajectory differed on several characteristics from other classes (younger age, more females, less childhood adversity, less somatic illnesses, lower neuroticism, higher extraversion). Older age, earlier age of onset and lower extraversion predicted poorest course trajectory.

Conclusions. MDD, Dysth and DD did not adequately match empirically derived course trajectories for unipolar depression. For the future classification of unipolar depression, it may be wise to retain the larger, heterogeneous category of unipolar depression, adopting cross-cutting dimensions of severity and duration to further characterize patients.

Received 17 April 2011; Revised 10 October 2011; Accepted 11 October 2011; First published online 7 November 2011

Key words: Course, depressive disorders, latent class growth analysis.

\section{Introduction}

From Kraepelin to modern times, the course trajectory has been an important criterion for validating psychiatric syndromes. In 1980, course was incorporated into the diagnostic criteria of various subtypes of depressive disorders of the Diagnostic and Statistical Manual (DSM), resulting in the diagnostic categories of major depressive disorder (MDD) and dysthymic disorder (Dysth). Over the years, various other unipolar depressive syndromes or subtypes have been defined, including double depression (DD: the co-occurrence of MDD and Dysth).

* Address for correspondence: Dr D. Rhebergen, Department of Psychiatry, VU University Medical Center Amsterdam,

A.J. Ernststraat 887, 1081 HL Amsterdam, The Netherlands.

(Email : d.rhebergen@ggzingeest.nl)
This diversity among depressive disorders has been the topic of debate, with much of the controversy focusing on whether MDD and Dysth are qualitatively distinct disorders or represent different ends of a severity continuum (Shankman \& Klein, 2002). The enormous overlap in diagnoses between MDD and Dysth (Klein et al. 2006) and the failure to demonstrate differences between MDD and Dysth on a broad range of demographic, clinical, psychosocial, family history and treatment response variables (Keller \& Lavori, 1984; Angst \& Wicki, 1991; McCullough et al. 2003) fuelled this debate. Judd et al. (2002) concluded that Dysth is an integral component of the longitudinal structure of MDD, with each symptom level representing a different phase of illness intensity, activity and severity (Judd \& Akiskal, 2000). By contrast, there is evidence to support the existence of specific diagnostic subtypes within the larger group of affective 
disorders, such as chronic depression (McCullough et al. 2003).

To study the validity of various depressive subtypes, statistical methods designed to cluster heterogeneous outcomes naturally occurring in the data can be helpful. Free from any a priori assumptions, datadriven techniques, such as latent class growth analysis (LCGA), that cluster persons based on their trajectories of a given outcome may thus result in a more empirically based classification that can then be compared with the DSM classification of unipolar affective disorders. This method can be used to determine whether different depressive subtypes based on course trajectories can be distinguished and to what extent this corresponds with the current diagnostic categories. To date, several studies have used this approach to assess course trajectories in depressive disorders across adolescence (Stoolmiller et al. 2005; Olino et al. 2010) and among mothers throughout the childrearing phase (Campbell et al. 2009; Skipstein et al. 2010), or among bereaved caregivers (Li 2005; Taylor et al. 2008). Colman et al. (2007) examined course trajectories over the life course among the general population. However, some of these studies were limited by the inclusion of men only (Stoolmiller et al. 2005), use of different measures or informants over time (Stoolmiller et al. 2005; Colman et al. 2007), or combined depressive and anxiety symptoms (Colman et al. 2007). Hence, comparison of latent course trajectories with current DSM categories for depressive subtypes is lacking.

In this study we aimed to identify clinically relevant course trajectories, derived from LCGA, in a large cohort of currently depressed subjects participating in the Netherlands Study of Depression and Anxiety (NESDA). To determine whether the identified classes represent different course trajectories, we briefly validated the classes by means of some external validators. Next, we compared the identified course trajectories with the current diagnostic categories of MDD, Dysth and DD. If DSM categories identify clinical course trajectories sufficiently, we would expect MDD to be the prominent diagnosis in a class with best course trajectory and, additionally, most persons with MDD should be allocated to the class with the best course trajectory. Likewise, Dysth should be the most prominent diagnosis in the class with a chronic course, albeit of moderate severity, and most persons with Dysth should be allocated to this class. Finally, we expected DD to be the most prominent diagnosis in the class, representing a chronic and severe course trajectory, and most persons with DD to be allocated to this particular class. In addition, because DSM categories suggest particular course trajectories, we examined to what extent DSM categories predict course trajectories. Finally, we explored the characteristics of each identified class and examined putative predictors of class membership, and hence course trajectory. In previous studies, sociodemographics, co-morbid anxiety disorders (Hayden \& Klein, 2001), age of onset of depressive symptoms (Klein et al. 1999; Angst et al. 2009), childhood adversity (Hayden \& Klein, 2001; Rhebergen et al. 2011), somatic co-morbidity (Angst et al. 2009), neuroticism (Hayden \& Klein, 2001; Rhebergen et al. 2011) and a family history of depression (Klein et al. 1999; Stoolmiller et al. 2005; Olino et al. 2010) have been demonstrated to predict course trajectories. However, some inconsistencies exist. In this study, we examine the predictive value of sociodemographics (age, gender, level of education), co-morbid anxiety disorder, age of onset, childhood adversity, number of somatic illnesses, neuroticism, extraversion, and the presence of a family member with depression for class membership.

\section{Method \\ Study sample}

The NESDA is designed to investigate the course and consequences of depressive and anxiety disorders. It is a multisite naturalistic cohort study of adults (aged 18-65 years) recruited from the general population, general practices, and mental health organizations. The method of recruitment was extensively described elsewhere (Penninx et al. 2008). The study protocol was approved by the Ethical Review Board of the VU University Medical Center and written informed consent was obtained from all participants. For the present analysis, we selected respondents from the NESDA baseline assessment with a 6-month MDD $(n=1115)$ and/or a 6-month Dysth $(n=305)$ (total $n=1158)$. Of the 1158 persons at baseline, $946(81.7 \%)$ could be followed up after 2 years. Attrition in the study population was higher among those with younger age [odds ratio (OR) 1.02], lower educational level (OR 1.08) and those with DD (OR 1.47), but was not associated with sex, MDD or Dysth. Attrition for the NESDA has been described more extensively elsewhere (Lamers et al. 2011). To exclude persons already in remission, we restricted the sample to 804 subjects with a 6-month depressive diagnosis who confirmed symptoms in the month prior to baseline at either the Composite Interview Diagnostic Instrument (CIDI) recency questions or the Life Chart Interview (LCI; Lyketsos \& Nestadt, 1994) recorded at baseline. Of this final sample, $65.4 \%$ were female, with a mean age of $42.0 \pm 12.2$ years and $11.6 \pm 3.3$ years of education. Diagnoses were established using CIDI version 
2.1, according to DSM-IV criteria (WHO, 1998). The CIDI is a structured interview with acceptable reliability and validity (Wittchen, 1994; Wittchen et al. 1996). It was administered by specially trained research staff.

\section{Measurements}

Symptoms of depression

The LCGA was based on depressive symptoms derived from the LCI (Lyketsos \& Nestadt, 1994). The LCI was assessed both at baseline and after 2 years of follow-up by a trained interviewer. Baseline LCI served to compute a measure of duration of depressive symptomatology. LCI at the 2-year follow-up provided the data for the LCGA. First, the occurrence of life events in a particular period was explored to refresh memory and then the presence of depressive symptoms was assessed during each month of the successive years. In addition, for each month with reported depressive symptoms, the self-reported burden of the symptoms was assessed on a five-point scale, ranging from no or minimal severity, to mild, moderate, severe, or very severe. As the LCI at follow-up retrospectively assessed the burden of depressive symptoms over 2 years, this resulted in 24 scores of perceived burden of depressive symptoms. None of the 804 respondents had missing data on the LCI at follow-up.

\section{External validators}

To assess the validity of the identified course trajectories, we examined the distribution of various putative validators across the identified classes. We examined the total scores on the 30-item Inventory of Depressive Symptomatology - Self Report version (IDS-SR, www.ids-qids.org; Rush et al. 1986, 1996), both at baseline and after 2 years. In addition, the percentage of decline in IDS score during 2 years of follow-up was calculated. Next, level of functioning was measured by total scores on the World Health Organization Disability Assessment Schedule II (WHO-DAS; Chwastiak \& Von Korff, 2003), both at baseline and after 2 years of follow-up. Again the percentage of improvement on the WHO-DAS over 2 years of follow-up was calculated. The WHO-DAS queries difficulties in various domains of life during the past 30 days. We computed total scores based on five domains of the WHO-DAS (cognition, mobility, self-care, interpersonal interactions, participation in society). Finally, we examined the presence of a 6-month CIDI diagnosis of depression and/or Dysth at follow-up.

\section{Depressive categories}

To compare the identified course trajectories with DSM-IV categories and also to examine the predictive value of DSM-IV categories on class membership, we examined the relative distribution of depressive disorders at baseline per class and across classes (i.e. the percentages of baseline disorders across the rows). A depressive disorder at baseline consisted of a 6-month CIDI MDD and/or Dysth at baseline. Three depression groups were defined: major depressive disorder (MDD) $(n=573)$ consisted of those fulfilling an MDD and no Dysth diagnosis; dysthymic disorder only (Dysth) $(n=34)$ consisted of those with a dysthymic disorder but not an MDD diagnosis; and DD $(n=197)$ was defined as Dysth with a co-morbid MDD, ignoring the sequence of onset of Dysth and MDD.

\section{Putative predictors of class membership}

Although DSM-IV depressive categories are partly based on course and severity measures, we examined additional course and severity markers. This enabled us to perform multivariate multinomial logistic regression analyses to test whether DSM-IV categories have some additional value in the prediction of class membership over other baseline severity and duration measures. As a measure of severity, we used IDS-SR at baseline. This measure was also used as a putative external validator for the identified course trajectories. As a measure of duration, we calculated the number of months with depressive symptoms prior to baseline, using LCI data from the past 5 years prior to baseline, recorded at baseline. Next, we examined the distribution of several other characteristics across the identified course trajectories and their predictive value on class membership (age, gender, level of education, co-morbid anxiety disorder, age of onset, childhood adversity, number of somatic illnesses, neuroticism, extraversion, and the presence of a family member with depression). Age was included as a continuous variable. Level of education was measured by years of education. Co-morbid anxiety disorder included a 6-month diagnosis of panic disorder (with or without agoraphobia); agoraphobia without history of panic disorder; social phobia and/or generalized anxiety disorder, as recorded by the CIDI. Age of onset of the index disorder was assessed in the CIDI. Earliest age was used for those with co-morbid disorders. Childhood adversity was assessed using a structured interview from the Netherlands Mental Health Survey and Incidence Study (NEMESIS; Bijl et al. 1998), in which respondents were asked to retrospectively recall whether they had experienced emotional neglect, psychological abuse, physical abuse or sexual abuse before the age of 16 years. A childhood index was 
computed (range 0-4), as used previously (Wiersma et al. 2009). The presence of somatic conditions was assessed in the baseline interview. A count of the number of somatic diseases (including cardiovascular disease, diabetes, lung disease, osteoarthritis, cancer, gastrointestinal disease, liver disease, epilepsy, thyroid disease) for which medical treatment is received was constructed. Neuroticism and extraversion were assessed by means of the neuroticism and extraversion dimension of the NEO (Neuroticism-ExtroversionOpenness) personality questionnaire, a 60-item questionnaire measuring five personality domains (Costa $\&$ McCrae, 1995). The presence of a depressive disorder in first-degree family members was assessed using the family tree method (Fyer \& Weissman, 1999).

\section{Statistical analyses}

To identify distinct classes based on different course trajectories, we performed LCGA, which is used to identify different classes of persons showing a comparable course of symptoms (Nylund et al. 2007). It starts with one class, suggesting one type of course fitting for all persons. Then successively more classes are added to determine the best-fitting model. Because LCGAs and other mixture models are susceptible to converging on local rather than global solutions (Nylund et al. 2007), we used multiple random starting values for the estimated models (500 repeats with 20 final optimizations). We increased the number of random starting values when necessary to avoid local solutions. We first fitted standard LCGA with intercept and linear effect of time. Then we successively added a quadratic and cubic slope factor to allow for curved trajectories. These additional growth factors will add computational burden and may add to convergence problems and model instability. Therefore, we fixed the variance and covariance estimates in all models to zero to aid convergence (Jung \& Wickrama, 2008). The LCI score was treated in the LCGA as a continuous variable. The LCGAs were conducted using M-plus version 5 (Muthén \& Muthén, 2007).

To determine which model best fitted the data, we combined the smallest Bayesian information criterion (BIC), the Lo-Mendell-Rubin (LMR) likelihood ratio test, entropy and proportions of the classes with interpretability and clinical relevance of the latent trajectory classes. Of the traditionally used information criteria, such as Aikaike's Information Criterion (AIC) and BIC, the latter performs best (Nylund et al. 2007). The accuracy of the AIC decreases as the sample size increases because there is no adjustment for sample size (Nylund et al. 2007). Lower BIC values indicate better model fit. The LMR test provides a $p$ value that indicates whether the $k-1$ class model is rejected in favor of the $k$ class model. Finally, entropy, as a measure of the quality of classification, is presented for models with more than one class, in addition to the proportions of individuals in each class. To identify clinically relevant classes, we only considered models with classes greater than $5 \%$.

After the identification of the classes, persons were assigned to their most likely class based on model probabilities. Then, we examined the validity of the identified classes by testing the distribution of the potential validators across classes, and we compared the characteristics of participants across the identified classes using two-tailed $\chi^{2}$ statistics for categorical variables and one-way analysis of variance (ANOVA) statistics for continuous variables. Additional pairwise comparisons were performed to test for differences between pairs of classes. Multivariate, multinomial logistic regression analyses were conducted to examine determinants of class membership. First, the association between DSM categories and class membership was examined (model 1). Second, the association between severity and duration measures and class membership was examined (model 2). Third, both DSM categories and severity and duration measures were combined in one model to test any additional predictive value of DSM categories above measures of severity and duration in predicting class membership (model 3). Fourth, the association between other characteristics and class membership was examined. All comparisons were conducted using SPSS version 15.0 (SPSS Inc., USA).

\section{Results}

In Table 1 the maximum likelihood values, the BIC, the entropy, the LMR likelihood ratio tests and the proportion of individuals in each class of each LCGA model are presented. The standard linear model provided a good representation of the various course trajectories. Addition of cubic and quadratic growth factors resulted in non-fitting models (data not shown). Non-convergence and solutions with inadmissible estimates occurred. Therefore, we altered the random starts to $2000 / 750$, but this still did not yield adequate estimates. To test the assumption that cubic or quadratic slopes might be present in some but not all classes, we tried to constrain each respective class to follow a linear model, while allowing the other classes cubic or quadratic trajectories. This also did not yield fitting models. Hence, both cubic and quadratic models were considered as non-fitting. Although the BIC values continued to diminish in the linear model, the LMR test failed to reach significance, from the 
Table 1. Parameters of fit of latent class growth analysis (LCGA)

\begin{tabular}{|c|c|c|c|c|c|c|c|c|c|c|c|c|}
\hline \multirow{2}{*}{$\begin{array}{l}\text { Linear } \\
\text { model }\end{array}$} & \multirow[b]{2}{*}{ Class } & \multirow{2}{*}{$\begin{array}{l}\text { Maximum } \\
\text { likelihood }\end{array}$} & \multirow[b]{2}{*}{$\mathrm{BIC}$} & \multirow[b]{2}{*}{ Entropy } & \multicolumn{2}{|l|}{ LMR test } & \multicolumn{6}{|c|}{ Proportion of individuals in class } \\
\hline & & & & & $2 \mathrm{LL}$ & $p$ & 1 & 2 & 3 & 4 & 5 & 6 \\
\hline 1.1 & 1 & & & & & & & & & & & \\
\hline 1.2 & 2 & -27123.643 & 54441.248 & 0.96 & 7895.32 & $<0.001$ & 0.58 & 0.42 & - & - & - & - \\
\hline 1.3 & 3 & -25956.525 & 52127.077 & 0.96 & 2334.24 & 0.04 & 0.16 & 0.50 & 0.34 & - & - & - \\
\hline 1.4 & 4 & -25267.652 & 50769.397 & 0.96 & 1377.75 & 0.03 & 0.10 & 0.49 & 0.15 & 0.26 & - & - \\
\hline 1.5 & 5 & -24752.198 & 49758.553 & 0.97 & 1030.90 & 0.01 & 0.44 & 0.24 & 0.10 & 0.15 & 0.07 & \\
\hline 1.6 & 6 & -24438.526 & 49151.274 & 0.97 & 627.344 & 0.42 & 0.23 & 0.09 & 0.43 & 0.09 & 0.05 & 0.12 \\
\hline
\end{tabular}

BIC, Bayesian Information Criterion; LMR, Lo-Mendell-Rubin; LL, log likelihood.

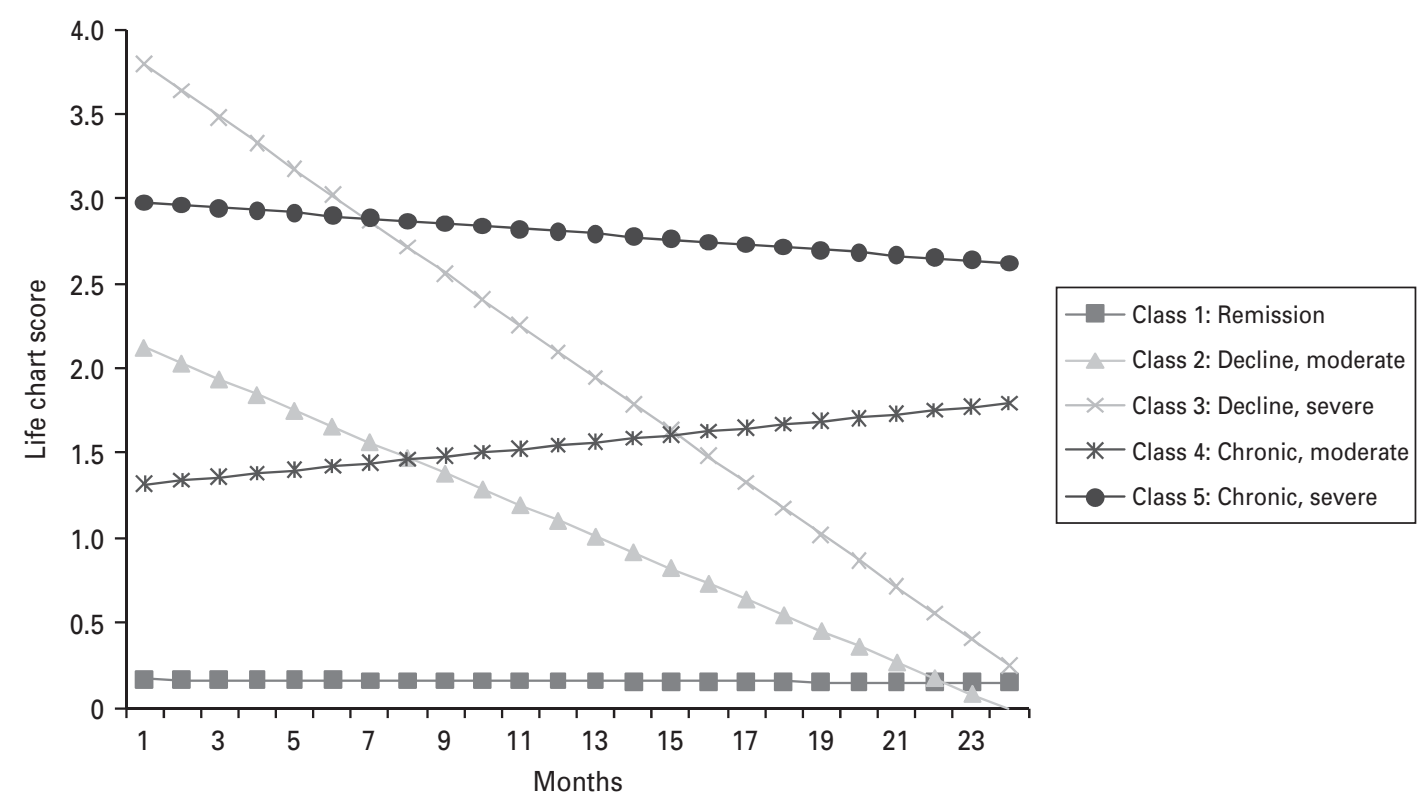

Fig. 1. Identified course trajectories, derived from latent class growth analysis (LCGA). To facilitate interpretation, class numbering corresponds to increasing severity and/or duration of depressive symptoms.

six-class model onwards. Hence, the five-class linear model provided the best fit for the observed data.

Figure 1 shows the course trajectories of the five latent classes identified. The first class (prevalence $44.3 \%$ ) was characterized by a rapid remission of symptoms. The second class (prevalence $24.1 \%$ ) showed a decline of symptoms, albeit slower than class 1 . In addition, the burden of depressive symptoms at baseline was higher compared to the first class. The third class (prevalence 9.8\%) showed a gradual decline of symptoms, but initial depression severity was higher than both previous classes. The fourth class (prevalence $15.0 \%$ ) had a chronic course trajectory, of moderate depression severity. Finally, the fifth class (prevalence $6.7 \%$ ) had a chronic course trajectory, with the highest burden of depressive symptoms.

\section{Validation of the course trajectories}

We tested the validity of the five-class model by examining the distribution of severity measures (IDS score, level of functioning) and measures of change (decline in IDS score, improvement in functioning) across the course trajectory classes identified (Table 2). As expected, both extremes, class 1 (remission) and class 5 (chronic severe), were markedly distinct from each other on all parameters. Next, we expected that classes of similar severity at baseline (classes 2 and 4 , classes 3 and 5) would not differ on baseline severity measures but would differ on measures of change. This was confirmed. In addition, we expected no differences between chronic course trajectories (classes 4 and 5) on measures of change (decline in IDS score, 
Table 2. Distribution of putative validators across the identified latent course trajectories

\begin{tabular}{|c|c|c|c|c|c|c|}
\hline & $\begin{array}{l}\text { Class } 1 \\
\text { (remission, } \\
\text { mild severity) } \\
n=356(44.3 \%)\end{array}$ & $\begin{array}{l}\text { Class } 2 \\
\text { (decline, } \\
\text { moderate } \\
\text { severity) } \\
n=194(24.1 \%)\end{array}$ & $\begin{array}{l}\begin{array}{l}\text { Class } 3 \\
\text { (decline, }\end{array} \\
\text { severe) } \\
n=79(9.8 \%)\end{array}$ & $\begin{array}{l}\text { Class } 4 \\
\text { (chronic, } \\
\text { moderate } \\
\text { severity) } \\
n=121(15.0 \%)\end{array}$ & $\begin{array}{l}\text { Class } 5 \\
\text { (chronic, } \\
\text { severe) } \\
n=54(6.7 \%)\end{array}$ & $\begin{array}{l}\text { Overall } \\
\text { statistics } \\
\chi^{2}(\mathrm{df}) / F(\mathrm{df}) \\
p \text { value }\end{array}$ \\
\hline IDS at baseline, mean (S.D.) & $30.3(10.8)$ & $35.6(10.4)$ & $38.6(10.5)$ & $35.7(11.5)$ & $41.1(9.9)$ & $\begin{array}{l}21.9(4) \\
<0.001\end{array}$ \\
\hline IDS at 2-year follow-up, mean (s.D.) & $18.1(9.8)$ & $25.3(12.1)$ & $28.8(13.4)$ & $28.0(13.0)$ & $33.4(11.6)$ & $\begin{array}{l}40.5(4) \\
<0.001\end{array}$ \\
\hline Percentage decline in IDS score during 2-year follow-up & $36.2(34.6)$ & $27.4(32.8)$ & $23.3(35.2)$ & $19.1(32.5)$ & $17.2(25.8)$ & $\begin{aligned} & 9.1(4) \\
< & 0.001\end{aligned}$ \\
\hline $\begin{array}{l}\text { Functioning (high score }=\text { low functioning) at baseline, } \\
\text { mean (s.D.) }\end{array}$ & $67.7(17.7)$ & $75.4(17.5)$ & $80.0(19.5)$ & $73.9(17.5)$ & $81.3(15.2)$ & $\begin{array}{l}15.0(4) \\
<0.001\end{array}$ \\
\hline $\begin{array}{l}\text { Functioning (high score = low functioning) after } \\
\text { 2-year follow-up, mean (s.D.) }\end{array}$ & $25.2(18.1)$ & $34.7(21.3)$ & $41.1(21.3)$ & $37.9(21.9)$ & $51.4(23.1)$ & $\begin{array}{l}29.9(4) \\
<0.001\end{array}$ \\
\hline Percentage improvement in functioning during 2-year follow-up & $63.5(25.6)$ & $54.8(24.8)$ & $48.1(26.3)$ & $50.1(24.0)$ & $37.1(25.4)$ & $\begin{array}{l}19.1(4) \\
<0.001\end{array}$ \\
\hline Current CIDI diagnosis of depression after 2-year follow-up, \% & 24.5 & 60.3 & 62.0 & 73.6 & 100 & $\begin{array}{l}185.8(4) \\
<0.001\end{array}$ \\
\hline
\end{tabular}

IDS, Inventory of Depressive Symptomatology; S.D., standard deviation; df, degrees of freedom.

Significant differences across classes $(p<0.05)$ : Class 1 versus 2 : all parameters significantly different; Class 1 versus 3 : all parameters significantly different; Class 1 versus 4 : all parameters significantly different; Class 1 versus 5 : all parameters significantly different; Class 2 versus 3 : IDS at baseline, IDS at 2 years (functioning baseline $p=0.06$ ), functioning 2 years, improvement in functioning; Class 2 versus 4: decline in IDS, CIDI disorder after 2 years (IDS at 2 years $p=0.06$ ); Class 2 versus 5: all parameters significantly different; Class 3 versus 4 : (IDS at baseline $p=0.07$ ), functioning baseline; Class 3 versus 5: IDS at 2 years, functioning at 2 years, improvement in functioning, CIDI disorder after 2 years; Class 4 versus 5 : all parameters significantly different, except change in IDS. 
improvement in functioning), whereas difference in severity measures were expected. This was also confirmed. The course trajectory over 2 years of class 3 (decline, severe) could only partly be confirmed by external validators. Despite expectations that class 3 (decline, severe) would improve over time, severity measures of class 3 after 2 years were more like those of class 4 (chronic, moderate) (no significant differences, except baseline severity measures) than class 2 (decline, moderate). In addition, we expected classes 3 (decline, severe) and 4 (chronic, moderate) to differ on all parameters. However, they only differed significantly in baseline functioning. To conclude, our LCGA-identified model could largely be confirmed by external validators.

\section{Depressive diagnoses}

As presented in Table 3, we tested the distribution of the baseline DSM-IV categories of MDD, Dysth and DD across the trajectory classes identified. As expected, comparisons of the relative distribution of depressive disorders per class showed that the percentage of MDD gradually and significantly declined when course trajectories worsened, whereas the percentage of DD gradually rose. In addition, the fourth class (chronic, moderate) had the highest relative percentage of persons with Dysth (9.1\%) and the fifth class (chronic, severe) had a relatively high percentage of persons with DD (44.4\%). However, when DSM categories represent clinically relevant course types, persons with MDD should mainly be allocated to the most favorable course trajectory, whereas persons with Dysth and DD should mainly be allocated to the chronic classes. To examine this assumption, we compared the distribution of baseline depressive disorders across classes (i.e. the percentages of baseline disorders across the rows). As expected, MDD was most prevalent among the rapidly improving, mild class (class 1, 50\%). However, almost two-thirds (61.7\%) of the persons with Dysth at baseline were allocated to the best course trajectory classes $(38.2 \%$ class $1 ; 23.5 \%$ class 2). Similarly, more than half of the persons with DD were allocated to the best course trajectory classes (28.4\% class $1 ; 26.4 \%$ class 2$)$, a significantly higher percentage compared to other classes. This is in contrast to our a priori assumptions.

To further test the association between DSM categories and course trajectories, we conducted multinomial multivariate logistic regression analyses. First, the association between DSM categories and class membership was examined (model 1) (reference class 1 ; rapid remission and mild severity). As shown in Table 4, the association between DD and class membership showed an increase in ORs across the classes. Dysth was associated with class 4 (chronic, moderate) only. Next, the association between severity and duration measures and class membership was examined (model 2). IDS score was associated with class membership, with the highest odds for the severe classes [class 3: OR 2.03, 95\% confidence interval (CI) 1.56-2.65; class 5: OR 2.56, 95\% CI 1.86-3.52]. Number of months was associated with classes 3, 4 and 5, with similar ORs. Finally, both DSM categories and severity and duration measures were examined in one multivariate, multinomial, logistic regression model to test whether DSM categories would have additional predictive value over duration and severity measures only, in predicting class membership (model 3). Whereas the IDS score continued to predict class membership, DD was only associated with class 5 (chronic, severe). Dysth still predicted class membership for class 4 .

\section{Characteristics of the classes and their predictive value on course trajectories}

Whereas class 1 significantly differed on a broad range of characteristics (lower age, more females, less childhood adversity, less somatic illnesses, lower neuroticism, higher extraversion) from the other classes, differences among the other four classes were less profound (Table 3). The fourth class (chronic, moderate) was significantly older than classes 1 and 3 and had a significantly higher number of somatic illnesses compared to classes 1 and 2 . In addition, the fifth class (chronic, severe) had a lower age of onset compared to classes 1, 3 and 4, and a higher number of family members with depression compared to classes 2 and 4 .

In multinomial multivariate logistic regression analyses (reference class 1; rapid remission and mild severity), lower extraversion was associated with class 2 (decline, severe) (OR 1.33, 95\% CI 1.08-1.67) (Table 4). Higher neuroticism was associated with class 3 (decline, severe). For the two chronic classes more predictors could be identified. A chronic course trajectory of moderate severity (class 4 ) was associated with being male (OR 1.59, 95\% CI 1.01-2.63), having more somatic illnesses (OR 1.26, 95\% CI 1.02-1.55) and a higher level of neuroticism (OR 1.40, 95\% CI 1.05-1.86). Similarly, a higher age (OR 1.45, 95\% CI 1.03-2.04), an earlier age of onset (OR 1.79, 95\% CI 1.23-2.63) and a lower level of extraversion (OR 1.49, 95\% CI 1.04-2.13) predicted poorest course trajectory (chronic, severe). First-degree family members with depression resulted in high odds for the poorest course trajectory (class 5) (OR 2.57, 95\% CI 0.75-8.76), albeit not reaching significance. In a post-hoc analysis comparing both chronic classes, a family history of depression was significantly associated with class 5 
Table 3. Distribution of putative risk factors across the identified latent course trajectories

\begin{tabular}{|c|c|c|c|c|c|c|}
\hline & $\begin{array}{l}\text { Class } 1 \text { (remission, } \\
\text { mild severity) } \\
n=356(44.3 \%)\end{array}$ & $\begin{array}{l}\text { Class } 2 \text { (decline, } \\
\text { moderate severity) } \\
n=194(24.1 \%)\end{array}$ & $\begin{array}{l}\text { Class } 3 \text { (decline, } \\
\text { severe) } \\
n=79(9.8 \%)\end{array}$ & $\begin{array}{l}\text { Class } 4 \text { (chronic, } \\
\text { moderate severity) } \\
n=121(15.0 \%)\end{array}$ & $\begin{array}{l}\text { Class } 5 \text { (chronic, } \\
\text { severe) } \\
n=54(6.7 \%)\end{array}$ & $\begin{array}{l}\text { Overall statistics } \\
\chi^{2}(\mathrm{df}) / F(\mathrm{df}), p \text { value }\end{array}$ \\
\hline \multicolumn{7}{|l|}{ Baseline DSM diagnosis } \\
\hline \multicolumn{7}{|l|}{ Depressive disorders in each class } \\
\hline MDD & 80.6 & 69.1 & 67.1 & 58.7 & 51.9 & \multirow{3}{*}{$46.0(8),<0.001$} \\
\hline Dysth & 3.7 & 4.1 & 0 & 9.1 & 3.7 & \\
\hline DD & 15.8 & 26.8 & 32.9 & 32.2 & 44.4 & \\
\hline \multicolumn{7}{|l|}{ Depressive disorders across classes } \\
\hline MDD ( $\%$ of MDD at baseline, $n=573$ ) & 50.0 & 23.4 & 9.3 & 12.4 & 4.9 & $35.4(4),<0.001$ \\
\hline Dysth ( $\%$ of Dysth at baseline, $n=34$ ) & 38.2 & 23.5 & 0 & 32.4 & 5.9 & $10.9(4), 0.03$ \\
\hline DD ( $\%$ of DD at baseline, $n=197$ ) & 28.4 & 26.4 & 13.2 & 19.8 & 12.2 & $33.7(4),<0.001$ \\
\hline \multicolumn{7}{|l|}{ Severity/duration } \\
\hline IDS at baseline, mean (s.D.) & $30.3(10.8)$ & $35.6(10.4)$ & $38.6(10.5)$ & $35.7(11.5)$ & $41.1(9.9)$ & $21.9(4),<0.001$ \\
\hline $\begin{array}{l}\text { Depressed months prior to } \\
\text { baseline, mean (s.D.) }\end{array}$ & $18.0(15.6)$ & $21.6(16.7)$ & $26.4(17.9)$ & $28.0(18.8)$ & $28.0(16.8)$ & $12.2(4),<0.001$ \\
\hline \multicolumn{7}{|l|}{ Other characteristics } \\
\hline Age (years), mean (s.D.) & $40.7(12.5)$ & $42.8(12.5)$ & $41.2(11.8)$ & $44.4(10.9)$ & 43.5 (11.6) & $2.8(4), 0.03$ \\
\hline Gender, \% female & 69.3 & 63.4 & 67.1 & 59.5 & 57.4 & $6.2(4), 0.18$ \\
\hline Education, mean (s.D.) & $11.7(3.2)$ & $11.5(3.3)$ & $11.2(3.1)$ & $11.3(3.5)$ & $11.9(3.8)$ & $0.7(4), 0.59$ \\
\hline $\begin{array}{l}\text { Co-morbid anxiety disorder } \\
\text { (any disorder), \% yes }\end{array}$ & 61.1 & 66.0 & 67.1 & 63.6 & 74.1 & $4.3(4), 0.37$ \\
\hline $\begin{array}{l}\text { Age of onset of depression (years), } \\
\text { mean (s.D.) }\end{array}$ & $27.8(12.2)$ & $28.1(13.1)$ & $27.6(13.8)$ & $28.1(12.7)$ & $22.4(11.6)$ & $2.4(4), 0.05$ \\
\hline Childhood trauma, mean (S.D.) & $1.1(1.1)$ & $1.3(1.2)$ & $1.4(1.3)$ & $1.4(1.3)$ & $1.4(1.3)$ & $2.6(4), 0.04$ \\
\hline No. of somatic illnesses, mean (s.D.) & $0.6(0.9)$ & $0.7(0.9)$ & $0.8(1.0)$ & $1.0(1.2)$ & $0.8(0.8)$ & $3.14(4), 0.01$ \\
\hline Neuroticism, mean (S.D.) & $41.5(6.8)$ & $43.3(6.4)$ & $44.5(5.7)$ & $43.6(6.3)$ & $44.3(4.9)$ & $6.6(4),<0.001$ \\
\hline Extraversion, mean (S.D.) & $34.2(6.6)$ & $31.8(6.1)$ & $31.4(7.2)$ & $31.9(5.8)$ & $30.5(7.0)$ & $8.8(4),<0.001$ \\
\hline Family history of depression, \% yes & 85.1 & 84.0 & 87.3 & 79.3 & 94.4 & $7.2(4), 0.13$ \\
\hline
\end{tabular}

MDD, Major depressive disorder; Dysth, dysthymia ; DD, double depression (=MDD + Dysth); IDS, Inventory of Depressive Symptomatology ; s.D., standard deviation; df, degrees of freedom.

Significant differences across classes ( $p<0.05)$ : Class 1 versus 2: MDD, DD, IDS baseline, months depressed, age, neuroticism, extraversion; Class 1 versus 3: MDD, DD, IDS baseline, months depressed, childhood adversity, neuroticism, extraversion; Class 1 versus 4: MDD, Dysth, DD, IDS baseline, months depressed, age, gender, childhood adversity, somatic illnesses, neuroticism, extraversion; Class 1 versus 5: MDD, DD, IDS baseline, months depressed, age of onset, childhood adversity, neuroticism, extraversion; Class 2 versus 3: (Dysth $p=0.07$ ), IDS baseline, months depressed; Class 2 versus 4: MDD (Dysth $p=0.07$ ), months depressed, somatic illnesses; Class 2 versus 5 : MDD, DD, IDS baseline, months depressed, family with depression; Class 3 versus 4: Dysth, age; Class 3 versus 5: Age of onset; Class 4 versus 5: IDS baseline, age of onset, family with depression. 
Table 4. Results from multivariate, multinomial, logistic regression analyses associating baseline diagnosis, severity and duration and other characteristics with the identified course trajectories, compared to the most favorable course trajectory (class 1: remission, mild severity; reference)

\begin{tabular}{|c|c|c|c|c|}
\hline & $\begin{array}{l}\text { Class } 2 \text { (decline, } \\
\text { moderate severity) }\end{array}$ & $\begin{array}{l}\text { Class } 3 \text { (decline, } \\
\text { severe) }\end{array}$ & $\begin{array}{l}\text { Class } 4 \text { (chronic, } \\
\text { moderate severity) }\end{array}$ & $\begin{array}{l}\text { Class } 5 \text { (chronic, } \\
\text { severe) }\end{array}$ \\
\hline \multicolumn{5}{|l|}{ Model 1: Baseline DSM diagnosis } \\
\hline \multicolumn{5}{|l|}{ Depressive disorder } \\
\hline MDD & Reference & Reference & Reference & Reference \\
\hline Dysth & $1.31(0.53-3.24)$ & No dysth in class 3 & $3.41(1.47-7.93)$ & $1.570 .34-7.32)$ \\
\hline $\mathrm{DD}$ & $1.98(1.29-3.05)$ & $2.51(1.45-4.34)$ & $2.81(1.73-4.55)$ & $4.38(2.37-8.10)$ \\
\hline \multicolumn{5}{|l|}{ Model 2: Severity/duration } \\
\hline IDS score at baseline $\mathrm{a}^{\mathrm{a}}$ & $1.61(1.33-1.95)$ & $2.03(1.56-2.65)$ & $1.49(1.19-1.87)$ & $2.56(1.86-3.52)$ \\
\hline No. of months depressed prior to baseline $\mathrm{a}^{\mathrm{a}}$ & $1.13(0.93-1.37)$ & $1.40(1.09-1.80)$ & $1.62(1.32-2.00)$ & $1.46(1.09-1.95)$ \\
\hline \multicolumn{5}{|c|}{ Model 3: Baseline DSM diagnosis, severity and duration } \\
\hline \multicolumn{5}{|c|}{ Depressive disorder } \\
\hline MDD & Reference & Reference & Reference & Reference \\
\hline Dysth & $1.35(0.54-3.41)$ & No dysth in class 3 & $2.80(1.16-6.76)$ & $1.58(0.33-7.70)$ \\
\hline DD & $1.53(0.93-2.54)$ & $1.31(0.68-2.52)$ & $1.44(0.81-2.56)$ & $2.35(1.13-4.88)$ \\
\hline IDS score at baseline $\mathrm{e}^{\mathrm{a}}$ & $1.59(1.31-1.93)$ & $1.99(1.52-2.60)$ & $1.50(1.20-1.89)$ & $2.48(1.80-3.42)$ \\
\hline No. of months depressed prior to baseline $\mathrm{a}^{\mathrm{a}}$ & $1.03(0.83-1.29)$ & $1.33(1.00-1.78)$ & $1.48(1.16-1.88)$ & $1.21(0.87-1.69)$ \\
\hline \multicolumn{5}{|l|}{ Model 4: Characteristics (full adjustment) } \\
\hline Higher age $^{\mathrm{a}}$ & $1.20(0.96-1.50)$ & $0.97(0.71-1.33)$ & $1.29(0.99-1.68)$ & $1.45(1.03-2.04)$ \\
\hline Female & $0.78(0.53-1.16)$ & $0.84(0.49-1.46)$ & $0.63(0.38-0.99)$ & $0.55(0.30-1.04)$ \\
\hline Higher education $^{\mathrm{a}}$ & $0.97(0.82-1.15)$ & $0.92(0.73-1.17)$ & $0.96(0.79-1.17)$ & $1.06(0.81-1.38)$ \\
\hline Co-morbid anxiety & $1.01(0.68-1.49)$ & $0.92(0.53-1.59)$ & $0.85(0.54-1.35)$ & $1.44(0.72-2.88)$ \\
\hline Earlier age of onset & $1.51(0.81-1.27)$ & $0.92(0.66-1.27)$ & $1.10(0.85-1.43)$ & $1.79(1.23-2.63)$ \\
\hline Childhood adversity $^{\mathrm{a}}$ & $1.08(0.93-1.26)$ & $1.15(0.93-1.42)$ & $1.19(0.99-1.43)$ & $1.08(0.84-1.39)$ \\
\hline Somatic illnesses ${ }^{a}$ & $0.97(0.79-1.19)$ & $1.15(0.89-1.50)$ & $1.26(1.02-1.55)$ & $1.16(0.84-1.59)$ \\
\hline Higher neuroticism $^{\mathrm{a}}$ & $1.25(0.98-1.58)$ & $1.50(1.08-2.10)$ & $1.40(1.05-1.86)$ & $1.28(0.86-1.91)$ \\
\hline Lower extraversion $^{\mathrm{a}}$ & $1.33(1.08-1.67)$ & $1.35(0.99-1.81)$ & $1.20(0.93-1.56)$ & $1.49(1.04-2.13)$ \\
\hline Family history of depression & $0.90(0.54-1.48)$ & $1.17(0.56-2.47)$ & $0.64(0.37-1.12)$ & $2.57(0.75-8.76)$ \\
\hline
\end{tabular}

MDD, Major depressive disorder; Dysth, dysthymia; DD, double depression (=MDD+Dysth); IDS, Inventory of Depressive Symptomatology; S.D., standard deviation.

${ }^{a}$ Reported per S.D. increase: IDS score at baseline S.D. $=11$; months depressed S.D. $=17$; age S.D. $=12$; education S.D. $=3$; childhood adversity S.D. $=1$; somatic illnesses S.D. $=1$; neuroticism S.D. $=7$; extraversion S.D. $=7$.

Values given as odds ratio (95\% confidence interval).

Bold is significant association $(p<0.05)$. 
(chronic severe) membership (OR 4.00, 95\% CI 1.1414.29 ) in addition to an earlier age of onset (reference class 4$)$.

\section{Discussion}

The aim of our study was to identify clinically relevant course trajectories in a large cohort of depressed subjects participating in the NESDA and to compare these with DSM categories of MDD, Dysth and DD. By implementing data-driven techniques, we identified five different course trajectories, ranging from mild severity and rapid remission to high severity and chronic course trajectory. LCGA enabled classification of course trajectories beyond the scope of DSM and produced detailed course trajectories, in which heterogeneity during course trajectories was taken into account.

More than $40 \%$ of the respondents had a rapid remission of the depressive symptoms (class 1) and differed significantly on a broad range of characteristics from the other classes, whereas $20 \%$ of the respondents had a chronic course trajectory (classes 4 and 5) that was associated with specific putative predictors of course. Spijker et al. (2002) found similar percentages of chronic course trajectories of depressed persons in a large 3-year follow-up population-based study, although they did not use a data-driven technique. A review by Nandi et al. (2009) described studies that identified distinct course trajectories of depressive symptoms in the general population and their determinants, based on data-driven techniques; whereas most studies included children, adolescents or young adults, six studies assessed depressive trajectories among adults, including specific samples, such as mothers (Campbell et al. 2009) or bereaved caregivers (Li, 2005; Taylor et al. 2008). Despite differences in sample and design, most studies identified several distinct course trajectories, with the most prevalent classes differing in severity of symptoms and often classifying a chronic course trajectory. Some studies also identified classes with increasing symptoms over time (Colman et al. 2007; Olino et al. 2010; Skipstein et al. 2010). As can be seen in Fig. 1, a worsening class is lacking in our model. As we limited our model to clinically relevant classes, representing at least $5 \%$ of the respondents, this class was not identified. In a higher-class model we indeed identified a small worsening class of less than $5 \%$ (data not shown).

Whereas in clinical practice depressive disorders are classified by DSM-IV categories, we now present a more empirically based classification of course trajectories, identified by data-driven techniques. The question is raised: are the DSM-IV depressive categories associated with meaningful clinical course trajectories, or are the course trajectories derived from LCGA, based on severity and duration measures, clinically more relevant? Our aim was to compare DSM categories with the identified classes. Although the distribution of MDD across classes was largely as expected, considerable numbers of Dysth $(61.7 \%)$ and DD $(54.8 \%)$ were allocated to the two most favorable classes (classes 1 and 2). These results are in line with our previous results on course trajectories of depressive disorders in a large population-based study (Rhebergen et al. 2009). In that study, we found that $50.0 \%$ of persons with Dysth at baseline were free from any diagnosis after 1 year, rising to $70.8 \%$ after 3 years. Similarly, $46.4 \%$ of persons with DD were free from any depressive diagnosis after 1 year, rising to $69.1 \%$ after 3 years. These results indicate that the current diagnostic categories do not accurately distinguish or predict clinically relevant course trajectories. Although Dysth and DD are by definition chronic disorders, both our previous work and the current results suggest heterogeneous course trajectories within these diagnostic DSM categories. To our knowledge, previous comparisons of identified course trajectories with DSM categories are limited. Olino et al. (2010) investigated the prevalence of lifetime DSM diagnoses in the identified course trajectories of depression and anxiety from adolescence to adulthood in a general population sample. They found a high percentage of persons with Dysth in the persistent depressed class. All persons in this class had a lifetime diagnosis of MDD and half had a lifetime diagnosis of Dysth. They concluded that this class represents chronic or DD. We found a similar number of persons with Dysth in our chronic, severe class: Dysth was present in $48.1 \%$ of the respondents. However, although percentages of Dysth and DD within classes were as expected, the division of baseline disorders across classes differed from expectations. The majority of persons with Dysth or DD at baseline were allocated to the milder classes. Because Olino et al. (2010) recruited high school students with a history of psychopathology and controls without psychopathology, they did not investigate whether persons with Dysth were allocated as expected to the chronic classes or not. In addition, they did not find a class with decreasing probability of depressive disorder. Comparison to our decreasing symptom classes is therefore hampered. Likewise, probably due to limited follow-up, we did not identify a class with increasing depressive symptoms. In the class with increasing probability of depressive disorder, Olino et al. (2010) identified only a small minority with dysthymia. They suggest that this class represents persons with brief, recurrent depressive episodes. A more extended 
follow-up would enable us to investigate the prevalence of Dysth in other course trajectories. Stoolmiller et al. (2005) investigated lifetime depressive diagnoses in the identified classes. None in the very low group, $5.7 \%$ in the moderate-decreasing group, $20.0 \%$ in the high-decreasing group and $29.2 \%$ in the highpersistent group were diagnosed with a lifetime depressive disorder. No distinction was made between MDD, Dysth or DD. In addition, this study only included men, hence limiting generalizability to the general population.

Comparison of DSM categories with measures of severity and duration, by means of multivariate, multinomial, logistic regression analyses, revealed that the IDS score was persistently identified as a predictor for class membership, duration was associated with class 3 and 4 membership, whereas the predictive value of DSM categories was only marginal. Dysth only predicted class 4 membership (chronic, moderate) and DD only predicted class 5 membership (chronic, severe). These results suggest the importance of a combination of severity and duration measures in predicting course trajectories. However, both Dysth and DD additionally predicted chronic course trajectories (class 1 reference), which suggests that these DSM-IV categories do have some additional predictive power above severity and duration measures only. In post-hoc analyses, comparing both chronic classes (class 4 reference), DSM-IV categories were no longer associated with course. We may conclude that DSM-IV categories predict chronic depression, compared to non-chronic depression, but they do not differentiate between chronic depressions. These findings are in line with previous research (Spijker et al. 2002; Ormel et al. 2004; Vuorilehto et al. 2009). An earlier (albeit non-longitudinal) latent class analysis (LCA) study in the general population also identified a differentiation in subclasses based on severity (Sullivan et al. 1998). In this context, McCullough et al. (2000, 2003) and Klein et al. (2006) suggested that the chronic versus non-chronic distinction with a cross-cutting dimension of severity constitutes an important source of heterogeneity in depression. Our results, based on data-driven techniques, support the suggestion of McCullough et al. (2003) to characterize depressive disorders on cross-cutting categories or dimensions, based on chronicity and severity of the index disorder. Continuous measurements, such as the LCI, might contribute to a more thorough classification of depressive disorders that better reflects clinical course trajectories.

The final aim was to examine the association between various characteristics and class membership. In multinomial regression analyses, we observed a preponderance of males, somatic illnesses and a higher level of neuroticism in class 4 (chronic, moderate), and a higher age, an earlier age of onset and lower extraversion in class 5 (chronic, severe) (class 1 reference). Of note, we found male sex to be associated with the poorest course trajectory. Previously, this was also demonstrated by Olino et al. (2010) in a sample of adolescents and young adults. They suggested that being female was more associated with transient and episodic forms of internalizing psychopathology. Both somatic co-morbidity (Angst et al. 2009) and an earlier age of onset of depression were previously associated with chronic depressions, compared to non-chronic depressions (Mondimore et al. 2006; Angst et al. 2009). Although most studies to date have not used data-driven techniques, Olino et al. (2010) did used LCGA and concluded that the persistent depression class they identified may reflect an earlyonset chronic form of depression $(>70 \%$ chance of being depressed at each time interval), whereas the second depression class they identified may reflect an adult-onset, episodic form of depression with $<25 \%$ chance of being depressed at each time interval. Because Olino et al. (2010) included adolescents, comparison with our results is hampered. However, a considerable number of persons in our study reported the onset of their depressive episodes prior to 18 years $(29.4 \%)$. The mean age of onset was $27.5 \pm 12.7$ years (median $=25.0$ years). Hence, many persons had their first depressive episode in adolescence. Klein et al. (1999) also demonstrated that the early-onset subtype was associated with a poorer course trajectory and also greater family history of mood disorders. In our model, family history of depression showed high odds (OR 2.57, 95\% CI 0.75-8.76) for the poorest course trajectory (class 5; class 1 reference), but this did not reach significance. Similarly, Angst et al. (2009) could not demonstrate significant differences between chronic and non-chronic depressions related to family history of depression. Some other studies based on data-driven techniques identified family history of depressive symptomatology as a predictor for poor course trajectories. Stoolmiller et al. (2005) found that parental depressive symptoms contributed to class discrimination, discriminating the high-persistent class from the other three classes. This finding was replicated by Olino et al. (2010), who concluded that this pattern suggests that persistent depression may represent a more familial form of the disorder.

Our findings on personality dimensions are in line with previous reports. Both high neuroticism and low extraversion were previously found to be associated with chronicity (Robison et al. 2009; Wiersma et al. 2011).

Previous studies failed to demonstrate significant differences between various chronic depressions on a 
variety of characteristics (Yang \& Dunner, 2001; McCullough et al. 2003). Klein et al. (2006) suggested that the nature of chronic depression varies over time within individuals, indicating that the various manifestations of chronic depression in DSM-IV do not represent distinct disorders. In post-hoc analyses, comparing both chronic classes (class 4, chronic, moderate and class 5, chronic severe) we found that age of onset and a family history of depression differentiated between the two chronic classes (4 and 5). Lyons et al. (1998) and, more recently, Kendler et al. (2009) suggested that early age of onset does typify a subtype of depressive disorders, with poorer course trajectories. Hence, our fifth class (chronic, severe), characterized by greater severity, an early age of onset and a higher familial loading, may typify a distinct subtype and may be informative for etiological research.

\section{Strengths and limitations}

The present study is one of the largest to date to longitudinally investigate the existence of depressive course types in a large cohort of depressed subjects by data-driven methods. Furthermore, a wide range of putative predictors was tested. However, it should be noted that LCGAs draw upon mathematical models that cannot account for a great variety of fluctuations in symptom levels. As Judd and colleagues (Judd \& Akiskal, 2000; Judd et al. 2002) state, there is strong evidence during the long-term course of illness that major, minor, dysthymic and subsyndromal symptoms wax and wane within the same patient and that these symptomatic periods are interspersed in the overall course within times when patients are in remission and symptom free. This pleiomorphic course cannot be described completely by LCGA. In addition, by excluding persons with a remitted depression, insight into the course trajectories of probable recurrent depression is not provided. This requires further research but falls outside the scope of this study. Likewise, LCI assessment over a more extended time period might identify course trajectories that could not be captured in the rather short timeframe of the current study, for example relapse symptomatology. Furthermore, it should be noted that classification of persons based on the most likely class membership may mean that for some persons classification is highly accurate, whereas for others the posterior probabilities lie much closer to each other, making classification less accurate. In subsequent analyses of class differences, these differences between persons are not taken into account, which may lead to distorted estimates and standard errors. However, in our model, mean posterior probabilities ranged from
0.96 to 0.97 across classes, indicating that assigning individuals to their class was performed with precision. Finally, LCIs retrospectively assess depressive symptoms and perceived burden, which is prone to recall bias.

To conclude, MDD, Dysth and DD did not adequately match empirically derived course trajectories for unipolar depression. For the future classification of unipolar depression, it may be wise to retain the larger, heterogeneous category of unipolar depression, adopting cross-cutting dimensions of severity and duration to further characterize patients. LCI information may be helpful in clinical practice because it combines both severity and course information. In addition, the identified putative predictors facilitate identification of persons at risk for chronic course trajectories in clinical care.

\section{Acknowledgements}

The infrastructure for the NESDA (www.nesda.nl) is funded through the Geestkracht program of the Netherlands Organization for Health Research and Development (ZonMw, grant no. 10-000-1002) and is supported by participating universities and mental health care organizations: VU University Medical Center, GGZ inGeest, Arkin, Leiden University Medical Center, GGZ Rivierduinen, University Medical Center Groningen, Lentis, GGZ Friesland, GGZ Drenthe, IQ Healthcare, Netherlands Institute for Health Services Research (NIVEL) and Netherlands Institute of Mental Health and Addiction (Trimbos).

\section{Declaration of Interest}

None.

\section{References}

Angst J, Gamma A, Rossler W, Ajdacic V, Klein D (2009). Long-term depression versus episodic major depression: results from the prospective Zurich study of a community sample. Journal of Affective Disorder 115, 112-121.

Angst J, Wicki W (1991). The Zurich Study. XI. Is dysthymia a separate form of depression? Results of the Zurich Cohort Study. European Archives of Psychiatry and Clinical Neuroscience 240, 349-354.

Bijl R, Van Zessen G, Ravelli A, De Rijk C, Langendoen Y (1998). The Netherlands Mental Health Survey and Incidence Study (NEMESIS) : objectives and design. Social Psychiatry and Psychiatric Epidemiology 33, 581-586.

Campbell SB, Morgan-Lopez AA, Cox MJ, McLoyd VC (2009). A latent class analysis of maternal depressive symptoms over 12 years and offspring adjustment in adolescence. Journal of Abnormal Psychology 118, 479-493. 
Chwastiak LA, Von Korff M (2003). Disability in depression and back pain: evaluation of the World Health Organization Disability Assessment Schedule (WHO DAS II) in a primary care setting. Journal of Clinical Epidemiology 56, 507-514.

Colman I, Ploubidis GB, Wadsworth MEJ, Jones PB, Croudace TJ (2007). A longitudinal typology of symptoms of depression and anxiety over the life course. Biological Psychiatry 62, 1265-1271.

Costa PT, McCrae RR (1995). Domains and facets: hierarchical personality assessment using the revised NEO personality inventory. Journal of Personality Assessment 64, 21-50.

Fyer AJ, Weissman MM (1999). Genetic linkage study of panic: clinical methodology and description of pedigrees. American Journal of Medical Genetics 88, 173-181.

Hayden EP, Klein DN (2001). Outcome of dysthymic disorder at 5-year follow-up: the effect of familial psychopathology, early adversity, personality, comorbidity, and chronic stress. American Journal of Psychiatry 158, 1864-1870.

Judd LL, Akiskal HS (2000). Delineating the longitudinal structure of depressive illness: beyond clinical subtypes and duration thresholds. Pharmacopsychiatry 33, 3-7.

Judd LL, Schettler PJ, Akiskal HS (2002). The prevalence, clinical relevance, and public health significance of subthreshold depressions. Psychiatric Clinics of North America 25, 685-698.

Jung T, Wickrama K (2008). An introduction to LCGA and GMM. Social and Personality Psychology Compass 2, 302-317.

Keller MB, Lavori PW (1984). Double depression, major depression, and dysthymia: distinct entities or different phases of a single disorder? Psychopharmacology Bulletin 20, 399-402.

Kendler KS, Fiske A, Gardner CO, Gatz M (2009). Delineation of two genetic pathways to major depression. Biological Psychiatry 65, 808-811.

Klein DN, Schatzberg AF, McCullough JP, Keller MB, Dowling F, Goodman D, Howland RH, Markowitz JC, Smith C, Miceli R, Harrison WM (1999). Early- versus late-onset dysthymic disorder: comparison in out-patients with superimposed major depressive episodes. Journal of Affective Disorders 52, 187-196.

Klein DN, Shankman SA, Rose S (2006). Ten-year prospective follow-up study of the naturalistic course of dysthymic disorder and double depression. American Journal of Psychiatry 163, 872-880.

Lamers F, Hoogendoorn A, Smit J, van Dyck R, Zitman FG, Nolen WA, Penninx BW (2011). Sociodemographic and psychiatric determinants of attrition in the Netherlands Study of Depression and Anxiety (NESDA). Comprehensive Psychiatry. Published online: 10 March 2011. doi:10.1016/ j.comppsych.2011.01.011.

Li LW (2005). From caregiving to bereavement: trajectories of depressive symptoms among wife and daughter caregivers. Journal of Gerontology 60, 154-168.

Lyketsos C, Nestadt G (1994). The life-chart method to describe the course of psychopathology. International Journal of Methods in Psychiatric Research 4, 143-155.
Lyons MJ, Eisen SA, Goldberg J, True W, Lin N, Meyer JM, Toomey R, Faraone SV, Merla-Ramos M, Tsuang MT (1998). A registry-based twin study of depression in men. Archives of General Psychiatry 55, 468-472.

McCullough JP, Klein DN, Borian FE, Howland RH, Riso LP, Keller MB, Banks PL (2003). Group comparisons of DSM-IV subtypes of chronic depression: validity of the distinctions, Part 2. Journal of Abnormal Psychology 112, 614-622.

McCullough JP, Klein DN, Keller MB, Holzer CE, Davis SM, Kornstein SG, Howland RH, Thase ME, Harrison WM (2000). Comparison of DSM-III-R chronic major depression and major depression superimposed on dysthymia (double depression): validity of the distinction. Journal of Abnormal Psychology 109, 419-427.

Mondimore FM, Zandi PP, Mackinnon DF, McInnis MG, Miller EB, Crowe RP, Scheftner WA, Marta DH, Weissman MM, Levinson DF, Murphy-Ebenez KP, Depaulo JR, Potash JB (2006). Familial aggregation of illness chronicity in recurrent, early-onset major depression pedigrees. American Journal of Psychiatry 163, 1554-1560.

Muthén LK, Muthén BO (2007). Mplus User's Guide. Fifth Edition. Muthén \& Muthén: Los Angeles, CA.

Nandi A, Beard JR, Galea S (2009). Epidemiologic heterogeneity of common mood and anxiety disorders over the lifecourse in the general population: a systematic review. BMC Psychiatry 9, 31.

Nylund KL, Asparouhov T, Muthén BO (2007). Deciding on the number of classes in latent class analysis and growth mixture modeling: a Monte Carlo simulation study. Structural Equation Modeling 14, 535-569.

Olino TM, Klein DN, Lewinsohn PM, Rohde P, Seeley JR (2010). Latent trajectory classes of depressive and anxiety disorders from adolescence to adulthood: description of classes and associations with risk factors. Comprehensive Psychiatry 51, 224-235.

Ormel J, Oldehinkel AJ, Nolen WA, Vollebergh W (2004). Psychosocial disability before, during, and after a major depressive episode: a 3-wave population-based study of state, scar, and trait effects. Archives of General Psychiatry 61, 387-392.

Penninx BW, Beekman AT, Smit JH, Zitman FG, Nolen WA, Spinhoven P, Cuijpers P, De Jong PJ, Van Marwijk HW, Assendelft WJ, Van der Meer K, Verhaak P, Wensing M, De Graaf R, Hoogendijk WJ, Ormel J, Van Dyck R (2008). The Netherlands Study of Depression and Anxiety (NESDA): rationale, objectives and methods. International Journal of Methods in Psychiatric Research 17, 21-140.

Rhebergen D, Batelaan NM, De Graaf R, Nolen WA, Spijker J, Beekman ATF, Penninx BWJH (2011). The 7-year course of depression and anxiety in the general population. Acta Psychiatrica Scandinavica 123, 297-306.

Rhebergen D, Beekman AT, De Graaf R, Nolen WA, Spijker J, Hoogendijk WJ, Penninx BW (2009). The three-year naturalistic course of major depressive disorder, dysthymic disorder and double depression. Journal of Affective Disorders 115, 450-459. 
Robison EJ, Shankman SA, McFarland BR (2009). Independent associations between personality traits and clinical characteristics of depression. Journal of Nervous and Mental Disorders 197, 476-483.

Rush AJ, Giles DE, Schlesser MA, Fulton CL, Weissenburger J, Burns C (1986). The Inventory for Depressive Symptomatology (IDS) : preliminary findings. Psychiatry Research 18, 65-87.

Rush AJ, Gullion CM, Basco MR, Jarrett RB, Trivedi MH (1996). The Inventory of Depressive Symptomatology (IDS): psychometric properties. Psychological Medicine 26, 477-486.

Shankman SA, Klein DN (2002). Dimensional diagnosis of depression: adding the dimension of course to severity, and comparison to the DSM. Comprehensive Psychiatry 43, 420-426.

Skipstein A, Janson H, Stoolmiller M, Mathiesen KS (2010). Trajectories of maternal symptoms of anxiety and depression. A 13-year longitudinal study of a population-based sample. BMC Public Health 10, 589.

Spijker J, De Graaf R, Bijl RV, Beekman AT, Ormel J, Nolen WA (2002). Duration of major depressive episodes in the general population: results from The Netherlands Mental Health Survey and Incidence Study (NEMESIS). British Journal of Psychiatry 181, 208-213.

Stoolmiller M, Kim HK, Capaldi DM (2005). The course of depressive symptoms in men from early adolescence to young adulthood: identifying latent trajectories and early predictor. Journal of Abnormal Psychology 114, 331-345.

Sullivan PF, Kessler RC, Kendler KS (1998). Latent class analysis of lifetime depressive symptoms in the National
Comorbidity Survey. American Journal of Psychiatry 155, 1398-1406.

Taylor DH, Ezell M, Kuchibhatla M, Ostbye T, Clipp EC (2008). Identifying trajectories of depressive symptoms for women caring for their husbands with dementia. Journal of the American Geriatrics Society 16, 322-327.

Vuorilehto MS, Melartin TK, Isometsa ET (2009). Course and outcome of depressive disorders in primary care: a prospective 18-month study. Psychological Medicine 39, 1697-1707.

WHO (1998). Composite International Diagnostic Interview (CIDI), version 2.1. World Health Organization: Geneva. Wiersma JE, Hovens JG, van Oppen P, Giltay EJ, van Schaik DJ, Beekman AT, Penninx BW (2009). The importance of childhood trauma and childhood life events for chronicity of depression in adults. Journal of Clinical Psychiatry 70, 983-989.

Wiersma JE, van Oppen P, van Schaik DJF, van der Does AJW, Beekman ATF, Penninx BWJH (2011). Psychological characteristics of chronic depression: a longitudinal cohort study. Journal of Clinical Psychiatry 72, 288-294.

Wittchen HU (1994). Reliability and validity studies of the WHO-Composite International Diagnostic Interview (CIDI): a critical review. Journal of Psychiatric Research 28, 57-84.

Wittchen HU, Zhao S, Abelson JM, Abelson JL, Kessler RC (1996). Reliability and procedural validity of UM-CIDI DSM-III-R phobic disorders. Psychological Medicine 26, 1169-1177.

Yang T, Dunner DL (2001). Differential subtyping of depression. Depression and Anxiety 13, 11-17. 